\title{
Cognitive deficits in patients with mild to moderate traumatic brain injury
}

\author{
Eliane Correa Miotto ${ }^{1,3}$, Fernanda Zanetti Cinalli², Valéria Trunkl Serrao ${ }^{1}$, \\ Glaucia Guerra Benute ${ }^{1}$, Mara Cristina Souza Lucia ${ }^{1,3}$, Milberto Scaff ${ }^{3}$
}

\begin{abstract}
Traumatic brain injury (TBI) is one of the most frequent causes of brain damage. Cognitive deficits reported in the literature after moderate to severe TBI include memory, language, executive functions, attention and information processing speed impairments. However, systematic studies on patients with mild TBI are scarce although neuropsychological changes are present. Objective: To investigate the cognitive functioning of patients with mild to moderate TBI. Method: We evaluated 12 patients with mild to moderate TBI using a comprehensive protocol (PN01) of neuropsychological tests. Results: There were significant deficits of episodic memory including immediate and delayed verbal memory recall, verbal recognition, immediate and delayed visual memory recall, naming, verbal fluency and information processing speed. Conclusion: These results emphasize the importance of comprehensive neuropsychological assessments even in cases of mild TBI in order to identify impaired and preserved functions providing adequate managing including rehabilitation programs for each case.
\end{abstract}

Key words: traumatic brain injury, cognitive deficits, mild to moderate level.

\section{Alterações neuropsicológicas em pacientes com traumatismo crânio encefálico leve- moderado}

\section{RESUMO}

Traumatismo craniencefálico (TCE) é uma das causas mais freqüentes de lesão cerebral. São relatados na literatura déficits cognitivos após TCE moderado-grave relacionados à memória, linguagem, funções executivas, atenção e velocidade de processamento de informações. Estudos em pacientes com TCE leve são escassos embora alterações neuropsicológicas sejam encontradas nestes pacientes. Objetivo: Investigar o funcionamento cognitivo de pacientes com TCE leve e moderado através de um protocolo abrangente (PN01) de testes neuropsicológicos. Método: Foram avaliados 12 pacientes com TCE leve e moderado. Resultados: Foram identificados déficits graves de memória episódica verbal para evocação imediata, tardia e de reconhecimento, de memória episódica visuo-espacial para evocação imediata e tardia, nomeação, fluência verbal nominal e velocidade de processamento de informações. Conclusão: Os resultados do estudo argumentam a favor da importância de avaliação neuropsicológica abrangente mesmo em casos de TCE leve a fim de se identificar funções comprometidas e preservadas, proporcionando condutas e programas de reabilitação adequados a cada caso.

Palavras-chave: traumatismo crânio encefálico, déficits cognitivos, grau leve e moderado.

\section{Correspondence \\ Eliane Correa Miotto \\ Division of Psychology / ICHC-FMUSP \\ Av. Dr Enéas de Carvalho 155 \\ 05403-900 São Paulo SP - Brasil \\ E-mail:ecmiotto@usp.br}

Received 22 July 2009

Received in final form 10 June 2010

Accepted 17 June 2010
To the World Health Organization (WHO), traumatic brain injury (TBI) is a public health issue ${ }^{1}$, because it is one of the largest causes of brain injury, resulting in high rates of morbidity and mortality ${ }^{2-4}$. However, with modern medicine and the progress of techniques for acute treatment of TBI victims, patient survival rate is in-

'Division of Psychology, IC, Hospital das Clínicas, University of São Paulo, Medical School, São Paulo SP, Brazil; ${ }^{2}$ Trainee in Neuropsychology, Division of Psychology, IC - Hospital das Clínicas, University of São Paulo, Medical School, São Paulo SP, Brazil; ${ }^{3}$ Department of Neurology, University of São Paulo, Medical School, São Paulo SP, Brazil. 
creasing. Consequently, the number of patients who survive with cognitive impairment is growing ${ }^{3-5}$.

TBI severity (mild, moderate, severe) depends on a number of factors, including type of injury (diffuse or focal), extension and location, resulting in different patterns of damage ${ }^{2}$. The Glasgow Coma Scale (GCS) is one of the most commonly used tools to evaluate the level of TBI severity ${ }^{6}$. It is based on the score for best motor and verbal response as well as minimum stimulus to cause eye opening (Severe Level: 3 to 8; Moderate Level: 9 to 12; and Mild Level: 13 to 15, according to the Advanced Trauma Life Support (ATLS), American College of Surgeons Committee on Trauma, Chicago, 2004).

The frontal lobes (especially the orbitofrontal region) and temporal lobes are particularly vulnerable to lesions caused by $\mathrm{TBI}^{2,5,7-9}$ due to their neuroanatomical localization. Bigler ${ }^{5}$ emphasizes mesial temporal lobe vulnerability, especially the hippocampus, with its connections to the fornix, associated to persistent post-concussional syndrome. This syndrome may occur in approximately $15 \%$ of mild TBI cases, with changes in attention, memory, information processing speed and presence of fatigue, headaches, nausea, and emotional instability, even when evidence of lesion is not present in brain imaging. Some authors argue for functional factors and others for organic factors as the cause of these changes ${ }^{5}$.

Amongst neuropsychological impairments caused by mild and moderate TBI, reduction of information processing speed ${ }^{7,10-12}$ is frequently reported in literature and it may contribute to deficits in attention ${ }^{10,11}$, orientation and executive functioning ${ }^{7,10-12}$. Impairments of executive functions affect mental flexibility, planning, self-monitoring, and problem solving ${ }^{2}$. These impairments can compromise other abilities, such as attention and memory ${ }^{13,14}$. After the period of post-traumatic amnesia (PTA), patients who experienced severe TBI may present memory disorders of variable intensity ${ }^{15}$; damages of short term and long term ${ }^{7,9-11,16,17}$ memory.

Changes in behavior and personality may be associated to TBI, such as reduction in motivation and self-esteem, difficulty with empathy ${ }^{7}$, emotional processing, loss of insight, psychosocial difficulties ${ }^{8}$, post-traumatic stress disorder, depression, anxiety, and fatigue $e^{5,7,8,12,18,19}$.

Around two to five years after experiencing mild to moderate TBI, most patients remain stable, even though some of them present some cognitive difficulties, which may be observed in daily life tasks?

Considering damage variability in cases of $\mathrm{TBI}^{2}$, neuropsychological assessment should be comprehensive allowing for a systematic analysis of various cognitive functions, and providing a background of global functioning of patients. Studies with systematic neuropsychological assessments in patients with mild-moderate TBI are rare.
Therefore, this study aimed at investigating the presence of cognitive changes in patients with mild to moderate TBI as well as associations between these changes and the localization of brain lesions.

\section{METHOD}

\section{Subjects}

The subjects were recruited from database that contains all neurological patients treated by the Neuropsychology staff at Hospital das Clinicas outpatient and ward. Sixteen patients were evaluated, but 4 were excluded because they did not correspond to the inclusion criteria: mild to moderate TBI and after 1 year of TBI.

The sample included 12 subjects with mild to moderate TBI. Patients with less than 1 year of TBI, with comorbidity or other neurological or healthy problems, including use of drugs and alcohol were excluded.

The Department of Neurology Ethics Committee FMUSP and CAPPesq (086/06) approved the project and all participants signed an Informed Consent Term.

\section{Instruments}

The main instruments consisted of clinical interview and neuropsychological tests. The aim of each one is described below.

\section{PN-01 Protocol}

Vocabulary (Wechsler Adult Intelligence Scale Wais III $)^{20}$ : To investigate verbal abilities and derivation of word meaning, which, together with Matrix Reasoning test, provides an estimate Intelligence Quotient (IQ) ${ }^{21}$;

Matrix Reasoning (Wechsler Adult Intelligence Scale - Wais III ${ }^{20}$ : Non-verbal abilities and non-verbal logic reasoning, which provide an estimate IQ;

Hopkins Verbal Learning Test - Revised (HVLT R $)^{22}$ : Episodic memory with immediate, delayed recall and recognition of verbal information;

Brief Visuospatial Memory Test - Revised (BVMT $-\mathbf{R})^{23}$ : Episodic memory with immediate, delayed recall and recognition of visual-spatial information;

Digits (Wechsler Adult Intelligence Scale - Wais III $)^{20}$ : Short term memory and working memory;

Wisconsin Card Sorting Test (WCST-Nelson version $)^{24}$ : Mental flexibility, abstraction and problem solving;

FAS (COWA - Controlled Oral Word Association) ${ }^{25}$ : Nominal verbal fluency, aspect related to executive functions, providing evidence of the ability to inhibit irrelevant responses;

Category - animals (COWA - Controlled Oral Word Association $)^{25}$ : Categorization fluency associated to semantic memory;

Boston Naming Test (BNT) $)^{25}$ : Language function: naming; 
Symbol Digit Modalities Test ${ }^{26}$ : Information processing speed;

Visual Object and Space Perception Battery (Vosp) ${ }^{27}$ : Visuoperceptive and visuospatial functions.

\section{Procedure}

All patients were evaluated at the outpatient clinic of University of São Paulo Neurology Division, Medical School using the $\mathrm{PN}-01$ protocol. The main functions assessed included memory, language, information processing speed, visuospatial, visuoperceptive, executive and intellectual functions. The assessment lasted for two and a half hours and was carried out in one day.

Results were analyzed according to norms of each standardized test taking into account sample age, gender and years of education. Descriptive analyses were carried out using SPSS v. 10 (means and standard deviations) of percentiles obtained from the norms of each test. This is a descriptive study due to the very small sample, that would not allow for a robust statistical analysis.

\section{RESULTS}

Subjects aged between 25 and 68 years, mean $(M)=$ 39.75 and standard deviation $(\mathrm{SD})=14.37,2$ to 13 years of formal education $(\mathrm{M}=8.33$ and $\mathrm{SD}=3.39)$ were evaluated from November 2006 to May 2008.

All subjects were evaluated with the GCS ( $M=12.75$ and $\mathrm{SD}=2.56$ ), 6 subjects were classified as mild TBI $(\mathrm{M}=14.8$ and $\mathrm{SD}=0.45)$ and 6 as moderate TBI $(\mathrm{M}=11.28$ and $\mathrm{SD}=2.43)$. The subjects were evaluated between 12 and 19 months of TBI $(M=14.08$ and $S D=2.02)$.

Amongst the patients studied, 8 presented left hemisphere and 4 right hemisphere lesions. The majority of the patients presented lesions to frontal region (50\%), as described in Table 1.

The main results showed a significant impairment on their information processing speed $(\mathrm{M}=5.3$ and $\mathrm{SD}=14)$. There were 10 patients showing this deficit accounting for $83 \%$ of the sample. The second most affected function was verbal episodic memory recognition, with 9 (75\%) patients presenting significant deficits ( $M=9.85$ and $\mathrm{SD}=19.9)$. Eight $(67 \%)$ patients presented impairments in immediate verbal recall $(\mathrm{M}=10.2$ and $\mathrm{SD}=21.9)$, delayed verbal recall $(M=9.55$ and $S D=19.5)$ and naming $(M=18.4$ and $S D=31.8)$. Seven (58\%) subjects showed an impairment in visuospatial immediate recall $(\mathrm{M}=20.6$ and $\mathrm{SD}=28.5)$ and nominal verbal fluency $(\mathrm{M}=8.4$ and $\mathrm{SD}=15)$. Six (50\%) patients presented deficits on visuospatial delayed recall $(\mathrm{M}=28.7$ and $\mathrm{SD}=38.6)$. Results can be seen in Table 2.

In terms of the associations between cognitive changes and localization of brain lesions, most patients with left frontal lesions presented important impairments especial-
Table 1. Sample distribution according to the area and hemisphere of the lesion.

\begin{tabular}{lccc}
\hline Lesion site & & $\mathrm{N}$ & $\%$ \\
\hline Parietal & $\mathrm{R}$ & 1 & 8.33 \\
Temporal & $\mathrm{R}$ & 1 & 8.33 \\
& $\mathrm{~L}$ & 1 & 8.33 \\
Frontal & $\mathrm{L}$ & 4 & 33.36 \\
FT & $\mathrm{R}$ & 1 & 8.33 \\
& $\mathrm{~L}$ & 1 & 8.33 \\
FTP & $\mathrm{R}$ & 1 & 8.33 \\
TP & $\mathrm{L}$ & 1 & 8.33 \\
PO & $\mathrm{L}$ & 1 & 8.33 \\
Total & & & 100 \\
Right hemisphere - total & & 4 & 33.36 \\
Left hemisphere - total & & 8 & 66.64 \\
Total & & & 100 \\
\hline R: & &
\end{tabular}

R: right hemisphere; L: left hemisphere; FT: fronto-temporal; FTP; frontotemporo-parietal; TP: temporo-parietal; PO: parieto-occipital.

ly on verbal episodic memory (delayed recall and recognition) and presented normal performance on visuospatial episodic memory (recognition), short-term memory, non-verbal skills and Intellectual Quotient (Intellectual Functions) as described in Table 3.

Patients with right and left hemisphere temporal lesions presented moderate to severe deficits in most cognitive functions. The results can be seen in Table 4 .

Significant impairments were observed on nominal verbal fluency, naming, and information processing speed in patients with left and right frontal-temporal lesions.

The patient with right parietal lesion showed moderate to severe deficits in most of the functions evaluated, with performance within an expected range only on naming and non-verbal intellectual abilities.

The patient with left temporal-parietal lesion presented severe deficits in verbal episodic memory (immediate, delayed recall and recognition), naming, categorical verbal fluency, information processing speed and normal performance on visuospatial immediate and delayed recall and recognition, short-term memory and visuoperceptive functions.

The patient with right frontal-temporal-parietal lesion had a moderate to severe impairment on all functions evaluated, except for visuoperceptive functions.

The patient with left parietal-occipital lesion showed a severe difficulty on information processing speed and nominal verbal fluency and moderate deficit on intelligence function. His memory, visuoperceptive and visu- 
Table 2. Performance average percentiles and standard deviation for right and left hemisphere lesioned patients concerning cognitive functions and percentile of classified subjects in accordance to standard testing used.

\begin{tabular}{|c|c|c|c|c|c|c|c|c|}
\hline \multirow[b]{2}{*}{ Cognitive functions } & \multirow[b]{2}{*}{$\begin{array}{l}\text { Cognitive } \\
\text { tests }\end{array}$} & \multirow[b]{2}{*}{$\begin{array}{l}\text { Average of } \\
\text { percentile } \\
\text { (SD) }\end{array}$} & \multirow{2}{*}{$\begin{array}{l}\text { Right hem. } \\
\text { Average of } \\
\text { percentile } \\
\text { (SD) }\end{array}$} & \multirow{2}{*}{$\begin{array}{l}\text { Left hem. } \\
\text { Average of } \\
\text { percentile } \\
\text { (SD) }\end{array}$} & \multicolumn{4}{|c|}{ Classification performance - N (\%) } \\
\hline & & & & & Preserved & $\begin{array}{l}\text { Mild } \\
\text { deficit }\end{array}$ & $\begin{array}{c}\text { Moderate } \\
\text { deficit }\end{array}$ & $\begin{array}{l}\text { Severe } \\
\text { deficit }\end{array}$ \\
\hline \multicolumn{9}{|l|}{ Verbal episodic memory } \\
\hline Immediate recall & HVLT-R & $10.2(21.9)$ & $0.1(0)$ & $15.3(25.8)$ & $1(8)$ & $2(17)$ & 0 & $8(67)$ \\
\hline Delayed recall & HVLT-R & $9.55(19.5)$ & $3.08(5.95)$ & $12.8(23.4)$ & $2(17)$ & $1(8)$ & $1(8)$ & $8(67)$ \\
\hline Recognition & HVLT-R & $9.85(19.9)$ & $3.28(4.55)$ & $13.1(24)$ & $2(17)$ & $1(8)$ & 0 & $9(75)$ \\
\hline
\end{tabular}

Visualspatial episodic memory

$\begin{array}{llccccccc}\text { Immediate recall } & \text { BVMT-R } & 20.6(28.5) & 3.8(6.81) & 28.9(31.8) & 4(33) & 1(8) & 0 & 7(58) \\ \text { Delayed recall } & \text { BVMT-R } & 28.7(38.6) & 3.75(6.84) & 41.2(42.3) & 4(33) & 2(17) & 0 & 6(50) \\ \text { Recognition } & \text { BVMT-R } & 15(10.74) & 7.5(2.88) & 18.75(11.39) & 5(42) & 2(17) & 5(42) & 0\end{array}$

Short-term memory

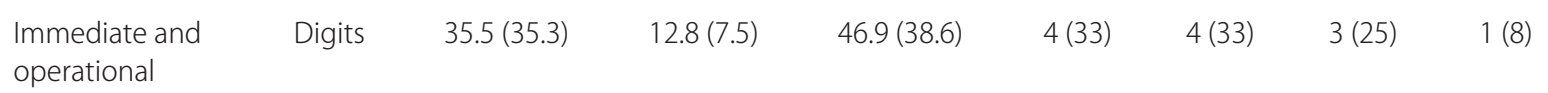

Language

$\begin{array}{llllllll}\text { Naming } & \text { Boston NT } & 18.4(31.8) & 16.6(33) & 19.3(33.4) & 3(25) & 1(8) & 0\end{array}$

Executive functions

$\begin{array}{lcccccccc}\text { Nom. v. fluency } & \text { FAS } & 8.4(15) & 2.8(3.6) & 11(19) & 1(8) & 2(17) & 2(17) & 7(58) \\ \text { Categ v. fluency } & \text { Category } & 18.7(24.25) & 3.42(5.72) & 26.34(26.64) & 6(50) & 1(8) & 2(17) & 3(25) \\ \text { Mental flexibility } & \text { WCST } & 32(29) & 33(36) & 26(28) & 5(42) & 1(8) & 2(17) & 4(33) \\ \text { IPS } & \text { Symbol } & 5.3(14) & 0.1(0) & 7.9(17) & 1(8) & 1(8) & 0 & 10(83)\end{array}$

Intellectual functions

\begin{tabular}{|c|c|c|c|c|c|c|c|c|}
\hline Verbal skills & Vocabulary & $22(29)$ & $14(17)$ & $28(34)$ & $4(33)$ & $2(17)$ & $2(17)$ & $4(33)$ \\
\hline Non-verbal skills & $\begin{array}{l}\text { Matrix } \\
\text { reasoning }\end{array}$ & $38(37)$ & $28(36)$ & $43(39)$ & $6(50)$ & $1(8)$ & $3(25)$ & $2(17)$ \\
\hline 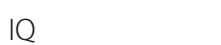 & & $24(29)$ & $11(17)$ & $30(33)$ & $5(42)$ & 0 & $5(42)$ & $2(17)$ \\
\hline
\end{tabular}

Visuo-perceptive functions

\begin{tabular}{|c|c|c|c|c|c|c|c|c|}
\hline $\begin{array}{l}\text { Incomplete } \\
\text { Letters }\end{array}$ & VOSP & $44.8(34.1)$ & $25.8(35.8)$ & $54.3(31.1)$ & $10(83)$ & 0 & 0 & $2(17)$ \\
\hline $\begin{array}{l}\text { Position } \\
\text { Discrimination }\end{array}$ & VOSP & $44(26.8)$ & $23.6(26.1)$ & $54.3(21.9)$ & $8(67)$ & $2(17)$ & $1(8)$ & $1(8)$ \\
\hline
\end{tabular}

SD: standard deviation; Hem.: hemisphere; N: number; IPS: information processing speed; IQ: intellectual quotient; HVLT-R: Hopkins Verbal Learning Test Revised; BVMT-R: Brief Visualspatial Memory Test - Revised; Boston NT: Boston Naming Test; Nom. V. fluency: Nominal verbal fluency; Categ. V. fluency: category verbal fluency; WCST: Wisconsin Card Sorting Test; VOSP: Visual Object and Space Perception Battery.

ospatial functions, mental flexibility and categorical verbal fluency were preserved.

\section{DISCUSSION}

This study aimed at evaluating overall cognitive performance of patients diagnosed with mild to moderate TBI, by means of The PN-01, a systematic protocol. The main results showed significant deficits in information processing speed, memory (verbal and visuospatial), language (naming) and executive functions.
Episodic memory and executive processes related to encoding, storage and retrieval, together with strategy formulation, were the main altered cognitive functions. In the literature, these changes are observed especially in moderate to severe cases of $\mathrm{TBI}^{13}$.

Most patients presented some level of difficulty, from mild to severe, on the administered tests. Nevertheless, in two of the 16 functions evaluated, they showed normal performance including on visuoperceptive and visuospatial functions. This finding can be possibly explained by 
Table 3. Average percentile and standard deviation and classification performance of patients with left frontal lesions concerning cognitive functions.

\begin{tabular}{|c|c|c|c|c|c|}
\hline \multirow[b]{3}{*}{ Cognitive function } & \multicolumn{5}{|c|}{ Frontal left lesions } \\
\hline & \multirow{2}{*}{$\begin{array}{c}\text { Average of } \\
\text { percentile (SD) }\end{array}$} & \multicolumn{4}{|c|}{ Classification performance - $\mathrm{N}(\%)$} \\
\hline & & Preserved & Mild deficit & Moderate deficit & Severe deficit \\
\hline \multicolumn{6}{|l|}{ Verbal episodic memory } \\
\hline Immediate recall & $23.3(35.9)$ & $1(25)$ & 0 & $2(50)$ & $2(50)$ \\
\hline Delayed recall & $6.9(13.4)$ & $1(25)$ & 0 & 0 & $3(75)$ \\
\hline Recognition & $0.22(0.25)$ & 0 & 0 & 0 & $4(100)$ \\
\hline \multicolumn{6}{|l|}{ Visualspatial episodic memory } \\
\hline Immediate recall & $27.9(33.6)$ & $2(50)$ & 0 & 0 & $2(50)$ \\
\hline Delayed recall & $34.8(40.1)$ & $2(50)$ & 0 & 0 & $2(50)$ \\
\hline Recognition & $21.5(11)$ & $3(75)$ & 0 & $1(25)$ & 0 \\
\hline \multicolumn{6}{|l|}{ Short-term memory } \\
\hline Immediate and operational & $71.2(38.3)$ & $3(75)$ & $1(25)$ & 0 & 0 \\
\hline \multicolumn{6}{|l|}{ Language } \\
\hline Naming & $26.1(43.1)$ & $1(25)$ & $1(25)$ & 0 & $2(50)$ \\
\hline \multicolumn{6}{|l|}{ Executive functions } \\
\hline Nominal verbal fluency & $21.5(22.6)$ & $1(25)$ & $1(25)$ & 0 & $2(50)$ \\
\hline Category verbal fluency & $14.8(7.1)$ & $2(50)$ & $1(25)$ & 0 & $1(25)$ \\
\hline Mental flexibility & $28.8(24.6)$ & $2(50)$ & $1(25)$ & 0 & $1(25)$ \\
\hline IPS & $15.1(23.8)$ & $1(25)$ & $1(25)$ & 0 & $2(50)$ \\
\hline \multicolumn{6}{|l|}{ Intellectual functions } \\
\hline Verbal skills & $43.7(41.98)$ & $2(50)$ & $1(25)$ & 0 & $1(25)$ \\
\hline Non-verbal skills & $57.7(40.1)$ & $3(75)$ & 0 & $1(25)$ & 0 \\
\hline $\mathrm{IQ}$ & $46.2(39.3)$ & $3(75)$ & 0 & $1(25)$ & 0 \\
\hline \multicolumn{6}{|l|}{ Visuoperceptive functions } \\
\hline Incomplete letters & $63.8(24.5)$ & $4(100)$ & 0 & 0 & 0 \\
\hline Position discrimination & 46.5 (30.9) & $3(75)$ & 0 & 0 & $1(25)$ \\
\hline
\end{tabular}

SD: standard deviation; IPS: information processing speed; IQ: intellectual quotient.

the preservation of occipital and posterior brain areas in many of the patients.

Most patients had frontal and temporal lesions and these regions are known to be particularly vulnerable to cognitive deficits related to memory and executive functions ${ }^{2,5-8,14}$. Patients with left frontal lesions presented more difficulties on verbal episodic memory, on both recognition and delayed recall, as well as, on executive functions.

Patients with right and left hemisphere temporal lesions presented a moderate to severe difficulty in most cognitive functions as patients with right parietal, left temporal-parietal and right frontal-temporal-parietal lesions.

In addition, cognitive impairments were observed on nominal verbal fluency, naming and information process- ing speed in patients with left and right frontal-tempo$\mathrm{ral}$ and left parietal-occipital lesions. These findings are in line with the literature showing participation of frontal and temporal areas in processes such as encoding, storage, and retrieval of information, in addition to, strategy and information processing speed ${ }^{13}$.

One limitation of the study is the relatively small number of samples, which did not allow for a robust statistical analysis. In spite of the small sample, it was possible to demonstrate that even mild to moderate TBI patients may show a range of mild to severe deficits in a variety of cognitive functions. It is possible that, since PNO1 is a detailed and systematic protocol, the current study was able to show a wide range of cognitive impairments in these subjects.

The current results also suggest that a systematic neu- 
Table 4. Classification performance of patients concerning localization of brain lesions and cognitive functions.

\begin{tabular}{|c|c|c|c|c|c|c|c|c|}
\hline \multirow[b]{3}{*}{ Cognitive function } & \multicolumn{8}{|c|}{ Classification performance concerning lesion localization (Percentile) } \\
\hline & \multirow{2}{*}{$\begin{array}{c}\text { Parietal } \\
\text { Right }\end{array}$} & \multicolumn{2}{|c|}{ Temporal } & \multicolumn{2}{|c|}{ Frontal temporal } & \multirow{2}{*}{$\begin{array}{c}\text { FTP } \\
\text { Right }\end{array}$} & \multirow{2}{*}{$\begin{array}{c}\text { TP } \\
\text { Left }\end{array}$} & \multirow{2}{*}{$\frac{\text { PO }}{\text { Left }}$} \\
\hline & & Right & Left & Right & Left & & & \\
\hline \multicolumn{9}{|l|}{ Verbal episodic memory } \\
\hline Immediate recall & Sev. $(<1)$ & Sev. $(<1)$ & Sev. (1) & Sev. $(<1)$ & Mod. (8) & Sev. (1) & Sev. $(<1)$ & Mild (21) \\
\hline Delayed recall & Sev. $(<1)$ & Sev. $(<1)$ & Sev. (1) & Mild (12) & Mod. (8) & Sev. (1) & Sev. $(<1)$ & Pres. (66) \\
\hline Recognition & Sev. (1) & Sev. (2) & Sev. (1) & Mild (10) & Pres. (50) & Sev. $(<1)$ & Sev. $(<1)$ & Pres. (54) \\
\hline \multicolumn{9}{|l|}{ Visualspatial episodic memory } \\
\hline Immediate recall & Sev. (1) & Sev. $(<1)$ & Sev. (1) & Mild (14) & Sev. $(<1)$ & Sev. $(<1)$ & Pres. (50) & Pres. (69) \\
\hline Delayed recall & Sev. $(<1)$ & Sev. $(<1)$ & Sev. (1) & Mild (14) & Mild (10) & Sev. $(<1)$ & Pres. (96) & Pres. (84) \\
\hline Recognition & Mild (10) & Mod. (5) & Mod. (5) & Mild (10) & Mod. (5) & Mod. (5) & Pres. (27) & Pres. (27) \\
\hline \multicolumn{9}{|l|}{ Short-term memory } \\
\hline Immediate and operational & Mod. (9) & Mild (24) & Sev. $(<1)$ & Mild (9) & Mild (24) & Mod. (9) & Pres. (50) & Mild (16) \\
\hline \multicolumn{9}{|l|}{ Language } \\
\hline Naming & Pres. (66) & Sev. $(<1)$ & Sev. $(<1)$ & Sev. $(<1)$ & Sev. $(<1)$ & Sev. $(<1)$ & Sev. $(<1)$ & Pres. (50) \\
\hline \multicolumn{9}{|l|}{ Executive functions } \\
\hline Nominal verbal fluency & Sev. (2) & Mod. (8) & Sev. $(<1)$ & Sev. (1) & Sev. $(<1)$ & Sev. $(<1)$ & Mod. (3) & Sev. $(<1)$ \\
\hline Category verbal fluency & Mild (12) & Sev. $(<1)$ & Mod. (7) & Sev. $(<1)$ & Mild (24) & Sev. $(<1)$ & Sev. $(<1)$ & Pres. (46) \\
\hline Mental flexibility & Sev. $(<1)$ & Pres. (50) & Sev. $(<1)$ & Pres. (75) & Mod. (9) & Sev. (2) & Mod. (9) & Pres. (75) \\
\hline IPS & Sev. $(<1)$ & Sev. $(<1)$ & Sev. $(<1)$ & Sev. $(<1)$ & Sev. $(<1)$ & Sev. $(<1)$ & Sev. (2) & Sev. $(<1)$ \\
\hline \multicolumn{9}{|l|}{ Intellectual functions } \\
\hline Verbal skills & Sev. (2) & Mild (14) & Sev. $(<1)$ & Pres. (37) & Mod. (9) & Sev. (1) & Pres. (34) & Mod. (4) \\
\hline Non-verbal skills & Pres. (37) & Sev. $(<1)$ & Mod. (5) & Pres. (75) & Pres. (84) & Sev. (1) & Mod. (5) & Mild (21) \\
\hline $\mathrm{IQ}$ & Mod. (5) & Mod. (3) & Sev. (2) & Pres. (37) & Pres. (37) & Sev. $(<1)$ & Mod. (9) & Mod. (9) \\
\hline \multicolumn{9}{|l|}{ Visuoperceptive functions } \\
\hline Incomplete letters & Sev. $(<1)$ & Sev. $(<1)$ & Sev. $(<1)$ & Pres. (27) & Pres. (76) & Pres. (76) & Pres. (76) & Pres. (27) \\
\hline Position discrimination & Mild (14) & Mod. (4) & Pres. (62) & Pres. (62) & Pres. (62) & Mild (14) & Pres. (62) & Pres. (62) \\
\hline
\end{tabular}

FTP: frontal temporal parietal lesion; TP: temporal parietal lesion; PO: parietal occipital lesion; IPS: information processing speed; IQ: intellectual quotient; Sev:: severe; Mod.: moderate; Pres.: preserved.

ropsychological evaluation could be a relevant investigation tool complementing clinical and neuroimaging exams by showing the cognitive impairments and preserved cognitive functions in this patient population. Systematic neuropsychological evaluations such as the $\mathrm{PN}-01$ protocol, may help to monitor changes on neuropsychological profiles of these patients and non-pharmacological treatments, such as neuropsychological rehabilitation, focused on specific cognitive domains. This protocol could be an important instrument to help on evaluation of patients after traumatic brain injury.

\section{REFERENCES}

1. World Health Organization. Neurotrauma. Available at http://www.who.int violence_injury_prevention/road_traffic/activities/neurotrauma/en/ - World Health Organization. Acessed june 202008.
2. Gouveia PAR, Fabrício AM. Avaliação neuropsicológica em traumatismo craniencefálico. In: Andrade VM, Santos FH, Bueno OFA (Eds). Neuropsicologia hoje. São Paulo: Artes Médicas 2004:297-305.

3. Koizume MS, Lebrão ML, Mello-Jorge MLP, Primerano V. Morbimortalidade por traumatismo crânio-encefálico no município de São Paulo, 1997. Arq Neuropsiquiatr 2000;58:81-89.

4. Plata CDM, Hart T, Hammond FM, et al. Impact of age on long-term recovery from traumatic brain injury. Arch Phys Med Rehabil 2008;89:896-903.

5. Bigler E. Neuropsychology and clinical neuroscience of persistent post-concussive syndrome. J Int Neuropsychol Soc 2008;14:1-22.

6. Teasdale G, Jennett B. Assessment of coma and impaired consciousness. A practical scale. Lancet 1974;2:81-84.

7. Fleminger S. Long-term psychiatric disorders after traumatic brain injury. Eur J Anaesthesiol Suppl 2008;42:123-130.

8. Saunders JC, McDonald S, Richardson R. Loss of emotional experience after traumatic brain injury findings with the startle probe procedure. Neuropsychology 2006;20:224-231.

9. Bigler ED. Anterior and middle cranial fossa in traumatic brain injury: relevant neuroanatomy and neuropathology in the study of neuropsychological outcome. Neuropsychology 2007;21:515-531. 
10. Hopkins R, Tate D, Bigler E. Anoxic versus traumatic brain injury: amount of tissue loss, not etiology alters cognitive and emotional function. Neuropsychology 2005;19:233-242.

11. Mathias J, Wheaton P. Changes in attention and information-processing speed following severe traumatic brain injury. Neuropsychology 2007;21:212-223.

12. O'Jile JR, Ryan $L M$, Betz $B$, et al. Information processing following mild head injury. Arch Clinic Neuropsychol 2006;21:293-296.

13. Strangman GE, O'Neil-Pirozzi TM, Goldstein R, et al. Prediction of memory rehabilitation outcomes in traumatic brain injury by using functional magnetic resonance imaging. Arch Phys Med Rehabil 2008;89:974-981.

14. Ghajar J, Richard BI. The predictive brain state: timing deficiency in traumatic brain injury? Neurorehabil Neural Repair 2008;22: 217-227.

15. Gil R. Neuropsicologia. São Paulo: Editora Santos 2005:1-297.

16. Christodoulou C, DeLuca J, Ricker JH, et al. Functional magnetic resonance imaging of working memory impairment after traumatic brain injury. J Neurol Neurosurg Psychiatry 2001;71:161-168.

17. Kurča E, Sivák S, Kučera P. Impaired cognitive functions in mild traumatic brain injury patients with normal and pathologic magnetic resonance imaging. Neuroradiology 2006;48:661-669.

18. Ziino C, Ponsford J. Selective attention deficits and subjective fatigue following traumatic brain injury. Neuropsychology 2006;20:383-390.
19. Iverson GL. Misdiagnosis of the persistent postconcussion syndrome in patients with depression. Arch Clin Neuropsychol 2006:21:303-310.

20. Nascimento E. WAIS-III: Escala de Inteligência Wechsler para adultos: manual David Wechsler - Adaptação e padronização de uma amostra brasileira. Silva MCVM (translation). São Paulo: Casa do Psicólogo 2004.

21. Ringe WK, Saine KC, Laura HL, et al. Dyadic Short Forms of the Wechsler Adult Intelligence Scale - III. Assessment 2002;9:254-260.

22. Brandt J, Benedict RHB. Hopkins Verbal Learning Test - Revised. Odessa: Psychological Assessment Resource 2001.

23. Benedict RHB. Brief Visualspatial Memory Test - Revised. Odessa: Psychological Assessment Resource 1997

24. Nelson HE. A modified card sorting test sensitive to frontal lobe deficits. Cortex 1976;12:313-324.

25. Strauss E, Sherman EMS, Spreen O. A compendium of neuropsychological tests: administration, norms, and commentary. $2^{\text {nd }}$ Edition. New York: Oxford University Press 1998.

26. Smith A. Symbol Digit Modalities Test. Los Angeles: WPS Western Psychological Services 2002.

27. Strauss E, Sherman EMS, Spreen O. A compendium of neuropsychological tests: administration, norms, and commentary. $3^{\text {rd }}$ Edition. New York: Oxford University Press 2006. 